Goldschmidt 2021 Abstract

https://doi.org/10.7185/gold2021.7546

\section{Magnesium isotope fractionation during natural travertine precipitation: an example from Baishuitai system (Yunnan, SW China).}

\author{
JIN CUN LIU ${ }^{1}$ AND JIUBIN CHEN ${ }^{2}$
}

${ }^{1}$ School of Earth System Science, Institute of Surface-Earth System Science, Tianjin University

${ }^{2}$ Tianjin university

Presenting Author: liujincun@tju.edu.cn

Travertine deposited in Earth's surface environments is an important geological archive for paleo-climatic reconstruction. As magnesium $(\mathrm{Mg})$ is a common element in carbonates, $\mathrm{Mg}$ isotope composition would provide useful information for studying paleo-climate evaluation history. However, until recently, studies focused mainly on laboratory experiments and reported inconsistent results on $\mathrm{Mg}$ isotope fractionation between Mg-calcite and aqueous solutions [1], highlighting further systematic research especially on the natural system.

Here, we investigate $\mathrm{Mg}$ isotope fractionation associated with calcite precipitation in the natural endogenic travertine deposition system, with samples collected along the canal at Baishuitai (Yunnan, SW China). The results display large $\delta^{26} \mathrm{Mg}$ variation from -1.37 to $-1.26 \%$ or the water samples, while relatively constant value for the solid travertine, and clear $\mathrm{Mg}$ isotope fractionation, with $\Delta^{26} \mathrm{Mg}_{\text {solid-solution }}$ values ranged from -2.76 to $-2.59 \%$ o (mean value of $-2.69 \%$ ). All natural travertine samples are thus enriched in ${ }^{24} \mathrm{Mg}$ compared to the water solution, in accord with previous experimental studies. All geochemical data strongly suggest a kinetic $\mathrm{Mg}$ isotope fractionation, rather than the equilibrium [2][3]. The $\mathrm{Mg}$ isotope variation along the canal could be eventually explained by the transition of $\mathrm{Mg}$ incorporation patterns downstream, with the direct coprecipitation of $\mathrm{Mg}$ cations into rapidly formed calcite at upstream, while an incorporation of $\mathrm{Mg}$ into the carbonate through an intermediate $\mathrm{Mg}$-rich amorphous calcium carbonate (ACC) formation at downstream. Though the relatively small temperature variation don't allow us to explore the temperature effect, as previous research [4], our study indicates clearly the usefulness of $\mathrm{Mg}$ isotopes in surface carbonate archives for reconstructing the paleo-climate, and noticeably the relative formation processes and mechanisms.

References: [1] Mavromatis et al. (2013), Geochim Cosmochim Acta 114, 188-203. [2] Young and Galy. (2004), Rev Mineral Geochem 55, 197-230. [3] Schott et al. (2016), Chem Geol 445, 120-134. [4] Li et al. (2012), Earth Planet Sci Lett 333-334, 304-316.

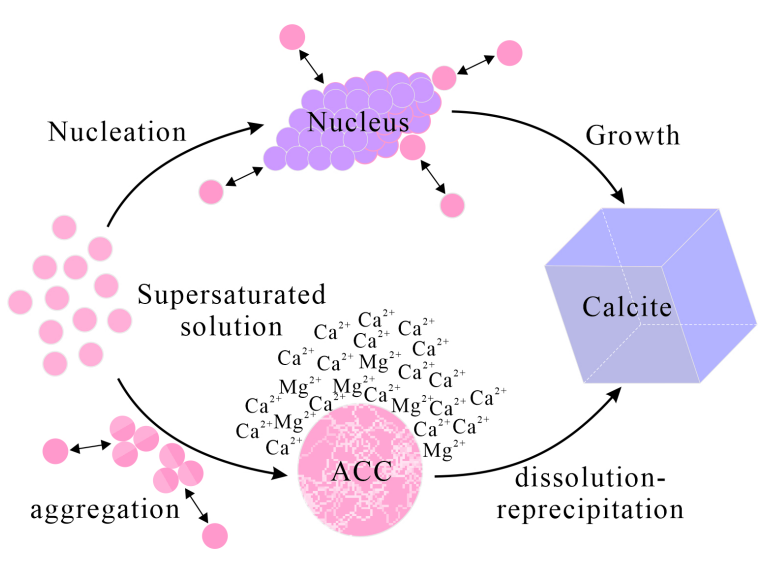

